\title{
Impacto de produtos fitossanitários utilizados na cultura do morangueiro sobre a população do predador Neoseiulus californicus (McGregor) (Acari: Phytoseiidae)
}

\author{
Juliano Antonio de Freitas ${ }^{1}$ \\ Luiz Carlos Dias Rocha \\ Rafaela Costa ${ }^{3}$ \\ Giovani Márcio Coura Júnior ${ }^{4}$ \\ Oliveiros Miranda dos Santos 5 \\ Éder Oliveira do Couto ${ }^{6}$
}

\section{Resumo}

Dentre as pragas prejudiciais à cultura do morangueiro, destaca-se o ácaro-rajado (Tetranychus urticae Koch, 1836), principal praga da cultura, cujo controle é, comumente, feito por meio do método químico. Neoseiulus californicus é um eficiente predador no controle desta praga. No presente estudo objetivou-se avaliar a seletividade de alguns produtos fitossanitários, utilizados na cultura do morangueiro em sistemas de produção integrada (PIMo) sobre o predador $N$. californicus em condições de laboratório, à exposição máxima, e semi-campo. O bioensaio foi conduzido no Laboratório de Entomologia do Instituto Federal de Educação Ciência e Tecnologia do Sul de Minas Gerais (IFSULDEMINAS), Campus Inconfidentes. Os produtos testados para os indivíduos de $N$. californicus, em g de i.a. $\mathrm{L}^{-1}$ de água, foram: abamectina $(0,072)$, enxofre $(2,400)$, fempropatrina $(0,195)$, propargito $(0,195)$, milbemectina $(0,009)$, cihexatina $(0,250)$, iprodiona $(0,750)$ e água. No presente bioensaio experimental foi realizada a aplicação direta das caldas dos produtos, por meio de pulverizadores calibrados, diretamente sobre predadores, sendo avaliada a mortalidade dos indivíduos. Abamectina foi considerada nociva, milbemectina e iprodiona apresentaram efeito prejudicial após 48 horas, porém com baixa toxicidade, enxofre, fempropatrina e propargito apresentaram baixa toxicidade, e Cihexatina não diferiu da testemunha ao predador $N$. californicus. Em termos de semi-campo, o composto Abamectina foi considerado seletivo.

Palavras chaves: Seletividade. Ácaro predador. Produtos químicos. Manejo Integrado de Pragas.

Mestrando em Entomologia/Acarologia, ESALQ/USP - freitas.usp@hotmail.com

Doutor em Entomologia, professor do IFSULDEMINAS, campus Inconfidentes. luiz.rocha@ifs.ifsuldeminas.edu.br

Tecnóloga em gestão ambiental e graduanda em agronomia do IFSULDEMINAS, campus Inconfidentes. costa.rafaela23@gmail.com Tecnólogo em gestão ambiental, Piracicaba, São Paulo.

IFSULDEMINAS, campus Inconfidentes

Tecnólogo em gestão ambiental IFSULDEMINAS, campus Inconfidentes, MG. 


\section{Introdução}

Os cultivos de morangueiros estão presentes, em sua grande maioria, em pequenas propriedades que praticam agricultura familiar, sendo esta uma cultura de grande relevância econômica pelo elevado emprego de mão de obra (RESENDE; MASCARENHAS; PAIVA, 1999; CARVALHO, 2006). Em consequência da elevada susceptibilidade da cultura às pragas e doenças, e também da realização de práticas agrícolas incorretas executadas por alguns agricultores, o morangueiro tem sido uma das culturas com maior utilização de pesticidas no Brasil.

Atualmente, no Brasil existe um grande número de projetos implantados e em fase de implantação envolvendo o Sistema Agropecuário de Produção Integrada (SAPI). Todos os sistemas visam a uma produção mais eficiente tecnicamente, menos impactante ambientalmente e que garanta a qualidade e rastreabilidade do produto ao consumidor. Para a cultura do morangueiro, o Ministério da Agricultura aprovou, em 2008, as normas do programa de Produção Integrada do Morangueiro (PIMo), em que o controle biológico é uma estratégia preconizada para o controle de pragas.

Além da escassez de estudos, poucas são as iniciativas de programas de controle biológico, o que dificulta a apropriação de tecnologias inovadoras e de baixo impacto ambiental pelos produtores de morango da região, justificando a necessidade da realização de estudos desta magnitude.

Minas Gerais destaca-se no cenário nacional como estado maior produtor de morango, com cerca de 72 mil toneladas por ano, em 1.790 hectares. Os números representam quase 55\% da produção nacional e garantem aproximadamente 26 mil empregos e o envolvimento de 5.900 produtores na atividade (EMATER-MG, 2011). A implantação da PIMo, no sul de Minas Gerais, permitirá que se tenha um produto diferenciado, que facilitará o comércio nacional e internacional, além de proporcionar a base para a concessão de um selo de qualidade controlada para os morangos produzidos nessa região do estado (ANTUNES et al., 2005).

Segundo Wetzel e Dickler (1994), para a viabilização de programas de manejo integrado ou de produção integrada, é importante que os produtos fitossanitários utilizados na cultura sejam inócuos ou seletivos aos inimigos naturais, e que estudos de seletividade sejam incentivados em condições de laboratório, semi-campo e campo.

A cultura do morangueiro apresenta alta susceptibilidade a diversas pragas em seus diferentes estádios fenológicos. As principais pragas são pulgões Capitophorus fragaefolii (COCKEREL, 1901), Cerosipha forbesi (WEED, 1889), formigas cortadeiras (Atta spp. e Acromyrmex spp.), lagarta rosca Agrotis ipsilon (HUFNAGEL, 1767) e os ácaros, que constituem o grupo mais danoso à cultura (FADINI; ALVARENGA, 1999).

No grupo dos ácaros-praga que atacam esta cultura, destaca-se o ácaro Tetranychus urticae Koch (Acari: Tetranychidae) como principal problema enfrentado por produtores do sul de Minas Gerais (FREITAS et al., 2011). São importantes pelo seu alto potencial biótico, elevado prejuízo provocado às plantas e pela dificuldade de seu controle com produtos fitossanitários convencionais. Após seu ataque, as folhas apresentam certa quantidade de teia, manchas branco-prateadas na face abaxial, queda e, como consequência, redução na produção (FLECHTMANN, 1985). Segundo English-Loeb e Hesler (2005) um limiar de 5 ácaros por folha de morangueiro é suficiente para provocar prejuízos à cultura.

Nas lavouras de morangueiros da região do sul do estado de Minas Gerais, o controle do ácarorajado é realizado principalmente pelo método químico e grande parte dos produtores apresenta pouco conhecimento sobre a utilização adequada dos defensivos (FREITAS et al., 2011), e em muitos cultivos a dificuldade de controle é grande devido à presença de populações resistentes aos principais grupos de agrotóxicos empregados.

Ácaros predadores da família Phytoseiidae são abundantes em cultura do morangueiro e têm como uma de suas fontes de alimento os ácaros tetraniquídeos (MCMURTRY; CROFT, 1997; 
MORAES, 2002). Entre estas espécies, N. californicus é um importante predador pertencente à família Phytoseiidae, que apresenta alta capacidade reprodutiva e, por alimentar-se de fontes alternativas de alimento (predador generalista), sobrevive em baixa população do ácaro-rajado (HODDLE; ROBINSON; VIRZI, 2000). Nos Estados Unidos, no sul da Califórnia, N. californicus têm sido utilizados no controle de ácaros tetraniquídeos em diversos cultivos, sendo também utilizados no cultivo do morangueiro (STRONG; CROFT, 1995; MCMURTRY; CROFT, 1997).

Tanto adultos quanto larvas e ninfas dos ácaros predadores apresentam boa capacidade de busca, sendo que um espécime adulto pode consumir um grande número de ovos de ninfas e até 7 adultos de ácaro-rajado/dia. Entretanto, o emprego de agrotóxicos prejudiciais aos predadores nas lavouras pode afetar o desempenho dos inimigos naturais e inviabilizar as estratégias de controle biológico.

Neste contexto, o presente estudo teve por objetivo avaliar o impacto de produtos fitossanitários utilizados na cultura do morangueiro sobre os predadores $N$. californicus, em condições de laboratório e semi-campo.

\section{Material e métodos}

Os bioensaios referentes às etapas de testes de laboratório foram realizados no Laboratório de Entomologia do Instituto Federal de Educação, Ciência e Tecnologia do Sul de Minas Gerais (IFSULDEMINAS), campus Inconfidentes.

Adultos e ninfas desta praga foram coletados em plantas de morangueiros de cultivos comerciais da região do Vale do Rio Mogi (município de Bom Repouso, sul de Minas Gerais) e levados ao laboratório para dar início à criação de manutenção. Foram mantidos sobre plantas de feijão-deporco (Canavalia ensiformes L.) cultivadas em vasos e mantidas em casa de vegetação. As plantas de feijão-de-porco foram substituídas em intervalos regulares para garantir a qualidade do alimento fornecido aos indivíduos. Assim, plantas novas foram dispostas ao lado de plantas atacadas para que ocorresse a migração natural do ácaro-rajado para a nova fonte alimentar, continuando, desta forma, o seu desenvolvimento.

\section{Obtenção e criação de manutenção dos ácaros predadores $\boldsymbol{N}$. californicus}

Adultos e ninfas do ácaro predador foram adquiridos da Empresa Promip (Paulínia - SP) e levados ao laboratório para iniciar a criação de manutenção.

Foram mantidos em câmaras climáticas sob condições controladas de $25 \pm 2{ }^{\circ} \mathrm{C}$, umidade relativa de $70 \pm 10 \%$ e fotofase de 14 horas, em plantas de feijão-de-porco cultivadas em vasos e previamente infestadas com o ácaro-presa T. urticae. As plantas de feijão-de-porco infestadas foram substituídas em intervalos regulares para garantir a quantidade de presa necessária ao desenvolvimento do predador. Para a substituição, plantas novas foram dispostas em contato com as plantas atacadas para que ocorra a migração natural do ácaro-rajado e do predador.

Antes do início dos experimentos, espécimes dos ácaros praga e do predador foram montados em lâminas e enviados a especialista para identificação das espécies a serem estudadas.

\section{Condução dos bioensaios}

Os produtos testados foram selecionados por serem recomendados para uso na cultura do morangueiro e por serem produtos bastante utilizados na região sul de Minas Gerais (Tabela 1). 0 tratamento testemunha foi composto apenas por água destilada. 
Tabela 1. Produtos fitossanitários utilizados para a avaliação do impacto sobre Neoseiulus californicus - Laboratório e semi-campo.

\begin{tabular}{ccccc}
\hline Ingrediente ativo & Produto Comercial & $\begin{array}{c}\text { Concentração/ } \\
\text { Formulação }\end{array}$ & $\begin{array}{c}\text { Dose } \\
\text { g i.a. L-1 água }\end{array}$ & Grupo Químico \\
\hline Abamectina $^{1}$ & Vertimec & $18 \mathrm{CE}$ & 0,072 & Avermectina \\
Enxofre & Tiovit Sandoz & $800 \mathrm{PM}$ & 2,400 & Inorganic \\
Fenpropatrina & Danimem & $300 \mathrm{CE}$ & 0,195 & Piretróide \\
Propargito & Omite & $720 \mathrm{EC}$ & 0,216 & Sulfito de alquila \\
Milbemectina & Milbeknock & $50 \mathrm{EC}$ & 0,009 & Milbemicinas \\
Cihexatina & Hokko Cyhexatin & $500 \mathrm{PM}$ & 0,250 & Organoestânico \\
Iprodiona & Rovral & $500 \mathrm{SC}$ & 0,750 & Dicarboximida \\
\hline
\end{tabular}

${ }_{1}^{1}$ Produto testado também em condições de semi-campo.

Fonte: Elaboração própria.

As aplicações dos produtos em fêmeas adultas de $N$. californicus foram realizadas conforme metodologia recomendada pela "International Organization for Biological and Integrated Control of Noxious Animals and Plants (IOBC), West Palaearctic Regional Section (WPRS)" (STERK; VANWESTSWINKEL, 1988; HASSAN, 1992; HASSAN, 1994; VEIRE; SMAGGHE; DEGHEELE, 1996; HASSAN, 1997; DEGRANDE et al., 2002).

As pulverizações dos produtos em fêmeas adultas de $N$. californicus foram realizadas por meio de pulverizadores manuais de $500 \mathrm{~mL}$ previamente calibrados, assegurando a aplicação de 1,5 a 2,0 mg de calda.cm-2.

Em cada tratamento, vinte e quatro (24) fêmeas adultas de $N$. californicus, com até 48 horas de idade e oriundas da criação em laboratório, foram acondicionadas em placas de Petri de 15 cm de diâmetro, fechadas com filme plástico de PVC e levadas para receberem os compostos via pulverização.

Para a obtenção das fêmeas de mesma idade, foram coletados ovos da criação e acompanhouse o desenvolvimento até a fase adulta. A diferenciação entre o macho e a fêmea foi realizada observando-se a morfologia da região do opistossoma, que se apresenta mais afilado na fêmea, que também tem o corpo maior em relação ao macho.

Após a pulverização, os indivíduos foram separados em 6 grupos de 4 indivíduos de $N$. californicus cada, e distribuídos sobre um disco foliar de feijão-de-porco de $4 \mathrm{~cm}$ de diâmetro, infestado previamente com a mesma quantidade da presa T. urticae. O disco foliar foi colocado sobre uma camada de algodão hidrófilo dentro de uma placa de Petri de $9 \mathrm{~cm}$ de diâmetro, fechada com um PVC. A camada de algodão foi umedecida diariamente. As placas foram mantidas em sala climatizada e sob condições controladas de $25 \pm 2^{\circ} \mathrm{C}$, umidade relativa de $70 \pm 10 \%$ e fotofase de 12 horas para as espécies de $N$. californicus.

O delineamento foi inteiramente ao acaso com oito tratamentos e seis repetições, constituídas de quatro indivíduos cada repetição.

As avaliações foram realizadas até o quarto dia após as aplicações dos produtos e foi registrado o número de ácaros mortos de fêmeas de $N$. californicus. A mortalidade dos ácaros foi avaliada após as pulverizações com auxílio de um microscópio estereoscópico (40x) e foi considerado morto o indivíduo que se manteve imóvel ao estímulo gerado pelo toque de um pincel. 


\section{Efeito dos produtos fitossanitários sobre fêmeas adultas de $\boldsymbol{N}$. californicus em casa de vegetação (semi-campo)}

O experimento foi realizado de acordo com a metodologia proposta pela IOBC (STERK; VANWESTSWINKEL, 1988; HASSAN, 1994; HASSAN, 1997; DEGRANDE et al., 2002). Foram utilizados neste experimento apenas aqueles produtos classificados como moderadamente nocivos ou nocivos ao predador nos experimentos anteriores, em laboratório, seguindo recomendações de Bakker et al. (1992).

Em plantas de morangueiro da cultivar 'Oso Grande', com idade uniforme (70 dias após transplantio), cultivadas em vaso, utilizando substrato Plantimax misturado com solo de barranco (Latossolo vermelho) na proporção de 1:1, foram pulverizadas as caldas dos produtos fitossanitários até o ponto de escorrimento. Os produtos foram aplicados utilizando-se um pulverizador manual de $600 \mathrm{~mL}$, que foi previamente calibrado para garantir a uniformidade na aplicação. Em seguida, as plantas foram acondicionadas em casa de vegetação.

Cerca de uma hora após a aplicação, foram distribuídas, em cada planta tratada, três gaiolas de PVC nos terços superior, médio e inferior, respectivamente, sendo uma gaiola por folha. As gaiolas foram de $3 \mathrm{~cm}$ de diâmetro e $1 \mathrm{~cm}$ de altura, fechadas na parte superior com tecido de nylon para evitar a fuga dos indivíduos e aberta na parte inferior para permitir o contato dos ácaros com a superfície foliar tratada. Novas gaiolas foram colocadas nas plantas após 7, 14, 21, 28 e 31 dias a partir da pulverização das caldas (HASSAN, 1997). Em cada gaiola foram liberadas 5 fêmeas de $N$. californicus para o experimento com este predador, juntamente com os ácaros-presa $T$. urticae como fonte de alimento, e 120 horas após o contato dos predadores com a superfície contaminada, a gaiola foi retirada e foi avaliada a sobrevivência dos espécimes.

O experimento foi conduzido em esquema de blocos ao acaso, composto de, no mínimo, oito repetições e dois tratamentos para o teste com $N$. californicus (Tabela 1 - dependente do resultado dos primeiros bioensaios realizados em laboratório).

\section{Análises estatísticas}

Os dados referentes à mortalidade acumulada dos indivíduos 1, 24, 48, 72, 96 e 120 horas após aplicação direta, foram submetidos à análise de variância em um modelo de parcelas subdivididas no tempo, com os produtos na parcela. Empregou-se o programa SISVAR (FERREIRA, 2008). 0 teste de Tukey a 5\% de significância foi usado para comparar as médias dos tratamentos nos casos em que o teste $F$ foi significativo.

\section{Classificação dos produtos segundo escala de toxicidade estabelecida pela IOBC}

Em função da mortalidade causada pelos produtos e seu efeito na capacidade de oviposição das fêmeas tratadas, foi calculado o efeito total ( $E \%$ ) utilizando-se da fórmula proposta por Bakker et al. (1992): $E=100 \%$ - (100\% - Ma), em que: $E=$ efeito total (\%) e Ma = mortalidade corrigida em função do tratamento testemunha (ABBOTT, 1925), em que: Ma = (Mt - Mc)/(100 - Mc) x 100 (Mt $=$ mortalidade observada no tratamento com o produto, $\mathrm{Mc}=$ mortalidade observada no tratamento testemunha).

a) testes em laboratório: os produtos foram então enquadrados em classes conforme a porcentagem de efeito total observado em: classe $1=$ inócuos $(E<30 \%$ ), classe $2=$ levemente nocivos (30\% $\leq \mathrm{E} \leq 80 \%)$, classe $3=$ moderadamente nocivos $(80 \%<\mathrm{E} \leq 99 \%)$ e classe $4=$ nocivos ( $\mathrm{P}>99 \%$ ), conforme escala proposta por membros da IOBC/WPRS (BAKKER et al., 1992; VEIRE; SMAGGHIE; DEGHEELE, 1996; HASSAN, 1997; DEGRANDE et al., 2002). 
b) testes em semi-campo: em função da toxicidade apresentada por cada produto, o mesmo foi classificado em uma das seguintes categorias, de acordo com HASSAN (1997): A = vida curta ( $<5$ dias), $\mathrm{B}=$ pouco persistente ( 5 a 15 dias), $\mathrm{C}=$ moderadamente persistente (16 a 30 dias) e $\mathrm{D}=$ persistente ( $>30$ dias).

\section{Resultados e discussão}

\section{Efeito dos produtos fitossanitários pulverizados diretamente sobre $\boldsymbol{N}$. califor- nicus}

Os resultados obtidos com a pulverização direta dos produtos fitossanitários sobre os predadores N. californicus após 1, 24, 48, 72, 96 horas são apresentados na Tabela 2.

0 efeito do abamectina mostrou-se prejudicial de maneira crescente a partir das 24 horas após a pulverização. Resultado semelhante ao obtido por Veronez et al. (2009) em espécimes de $P$. macropilis. 0 modo de ação do abamectina em artrópodes provoca efeito calmante, semelhante ao ácido gama-aminobutírico (GABA) (CLELAND, 1996). Milbemectina e iprodiona apresentaram efeito prejudicial após 48 horas, porém, com baixa toxicidade. As aplicações com enxofre, fempropatrina e propargito apresentaram baixa toxicidade ao predador $N$. californicus. Cihexatina não diferiu da testemunha 96 horas após aplicação sobre os espécimes.

Os estudos de compatibilidade de Veronez et al. (2009) realizaram aplicações com fempropatrina, iprodiona, enxofre e propargito sobre o predador $P$. macropilis. Os autores constataram que os produtos utilizados foram inócuos e comportaram-se de maneira semelhante aos resultados obtidos neste trabalho com a espécie $N$. californicus. Em estudos de compatibilidade de produtos fitossanitários, Poletti, Colletti e Omoto (2008) realizaram aplicações com fempropatrina, iprodiona, milbemectina sobre o predador $N$. californicus e constataram que estes foram considerados inócuos ao predador $N$. californicus. No presente trabalho, fempropatrina apresentou comportamento semelhante, porém iprodiona comportou-se como levemente nocivo. Essa diferença pode estar relacionada às dosagens empregadas, de $500 \mathrm{mg}$ i.a. $\mathrm{L}^{-1}$ contra $750 \mathrm{mg}$ i.a. $\mathrm{L}^{-1}$, usada no presente estudo. Em estudos realizados por Carvalho, Carvalho e Ferreira (2011), sobre Ceraeochrysa cubana, cihehatina apresentou-se como seletivo a esta espécie, semelhante aos resultados obtidos neste trabalho sobre espécies de $N$. californicus.

\section{Classificações dos produtos quanto ao efeito total sobre $\boldsymbol{N}$. californicus, se- gundo escala de toxidade estabelecida pela IOBC}

O princípio ativo abamectina foi considerado nocivo ao predador quando pulverizado diretamente sobre os espécimes, sendo enquadrado na classe 4. Milbemectina, propargito e iprodiona apresentaram-se como levemente nocivos, enquadrando-se na classe 2. Os compostos, enxofre, fempropatrina e cihexatina apresentaram-se como inócuos, enquadrando-se na classe 1 (Tabela 3).

\section{Efeito dos produtos fitossanitários sobre $\boldsymbol{N}$. californicus em condições de semi-campo}

Tendo em vista o baixo impacto dos demais compostos sobre Neoseiulus californicus em testes de laboratório, a fase de semi-campo foi realizada apenas com o abamectina e os resultados encontram-se a seguir (Tabela 4). 
Tabela 2. Mortalidade (\%) de adultos de Neoseiulus californicus após 1, 24, 48, 72 e 96 horas desde a aplicação dos produtos fitossanitários. Temperatura de $25 \pm 2^{\circ} \mathrm{C}$ e UR de $70 \pm 10 \%$

\begin{tabular}{cccccc}
\hline \multirow{2}{*}{ Tratamentos } & \multicolumn{5}{c}{ Mortalidade (\%) } \\
\cline { 2 - 6 } & $\mathbf{1}$ hora & $\mathbf{2 4}$ horas & $\mathbf{4 8}$ horas & $\mathbf{7 2}$ horas & $\mathbf{9 6}$ horas \\
\hline Abamectina & $13,4 \mathrm{a}$ & $46,6 \mathrm{~b}$ & $93,4 \mathrm{c}$ & $93,4 \mathrm{c}$ & $100 \mathrm{~d}$ \\
Enxofre & $6,6 \mathrm{a}$ & $13,4 \mathrm{a}$ & $26,6 \mathrm{a}$ & $40,0 \mathrm{a}$ & $46,6 \mathrm{~b}$ \\
Fempropatrina & $6,6 \mathrm{a}$ & $13,4 \mathrm{a}$ & $33,4 \mathrm{a}$ & $40,0 \mathrm{a}$ & $46,6 \mathrm{~b}$ \\
Propargito & $13,4 \mathrm{a}$ & $13,4 \mathrm{a}$ & $13,4 \mathrm{a}$ & $26,6 \mathrm{a}$ & $53,4 \mathrm{~b}$ \\
Milbemectina & $6,6 \mathrm{a}$ & $6,60 \mathrm{a}$ & $46,6 \mathrm{~b}$ & $66,6 \mathrm{~b}$ & $66,6 \mathrm{c}$ \\
Cihexatina & $6,6 \mathrm{a}$ & $13,4 \mathrm{a}$ & $20,0 \mathrm{a}$ & $20,0 \mathrm{a}$ & $26,6 \mathrm{a}$ \\
Iprodiona & $0,00 \mathrm{a}$ & $13,4 \mathrm{a}$ & $46,6 \mathrm{~b}$ & $53,4 \mathrm{a}$ & $66,6 \mathrm{c}$ \\
Testemunha & $0,00 \mathrm{a}$ & $13,4 \mathrm{a}$ & $13,4 \mathrm{a}$ & $26,6 \mathrm{a}$ & $26,6 \mathrm{a}$ \\
\hline CV(\%) & 150, & 138,6 & 38,7 & 39,8 & 28,3 \\
\hline
\end{tabular}

*Médias seguidas pela mesma letra minúscula na coluna não diferem entre si pelo teste de Tukey a $5 \%$ de significância.

Fonte: Elaboração própria.

Tabela 3. Efeito de produtos fitossanitários sobre a mortalidade (\%) de Neoseiulus californicus tratados na fase adulta, efeito (E) (\%) e classificação pela escala de toxicidade proposta pela IOBC. Temperatura de $25 \pm 2^{\circ} \mathrm{C}$, UR de $70 \pm 10 \%$ e fotofase de 12 horas. Inconfidentes, MG, IFSULDEMINAS, 2011.

\begin{tabular}{cccccc}
\hline Tratamentos & $\mathbf{N}^{\circ}$ de indivíduos & Mortalidade & MA (\%) & $\mathbf{E}(\%)^{2}$ & Classe $^{\mathbf{3}}$ \\
\hline Abamectina & 24 & 100,0 & 100,0 & 100,0 & 4 \\
Enxofre & 24 & 45,83 & 27,77 & 27,77 & 1 \\
Fempropatrina & 24 & 45,83 & 27,77 & 27,77 & 1 \\
Milbemectina & 24 & 66,66 & 55,55 & 55,55 & 2 \\
Propargito & 24 & 54,17 & 38,89 & 38,89 & 2 \\
Cihexatina & 24 & 25,00 & - & - & 1 \\
Iprodiona & 24 & 66,66 & 55,55 & 55,55 & 2 \\
Testemunha & 24 & 25,00 & - & - & - \\
\hline
\end{tabular}

${ }_{1}^{1}$ A mortalidade foi corrigida conforme a fórmula: $\mathrm{Ma}=(\mathrm{Mt}-\mathrm{Mc}) /(100-\mathrm{Mc}) \times 100$; (ABBOTT, 1925).

${ }^{2}$ Efeito total do produto sobre o inimigo natural, onde: $E=100 \%-(100 \%-\mathrm{Ma})$;

${ }^{3}$ Classe de toxicidade: classe $1=$ Inócuo $(E<30 \%)$, classe $2=$ levemente nocivo $(30 \% \leq E \leq 80 \%)$, classe 3 $=$ moderadamente nocivo $(80 \%<\mathrm{E} \leq 99 \%)$ e classe 4 = nocivo $(\mathrm{E}>99 \%)$ (VEIRE; STERK; STAAIJ, 2002).

Fonte: Elaboração própria.

Abamectina, na concentração testada, não provocou nenhum efeito sobre a mortalidade de $N$. californicus em condições de semi-campo e foi considerado produto de vida curta nestas condições (Tabela 4). 
Tabela 4. Porcentagem de mortalidade de adultos de Neoseiulus californicus em diferentes períodos de avaliação (persistência dos compostos) em condições de semi-campo e classes de toxicidade (IOBC/WPRS). Temperatura $25 \pm 5^{\circ} \mathrm{C}$; UR $70 \pm 15 \%$; fotofase de 14 horas.

\begin{tabular}{|c|c|c|c|c|c|c|c|c|c|c|c|}
\hline \multirow{3}{*}{ Tratamento } & \multicolumn{10}{|c|}{ Porcentagem de mortalidade/período de avaliação/classificação IOBC } & \multirow{3}{*}{$\begin{array}{c}\text { Classificação } \\
\text { final }^{2}\end{array}$} \\
\hline & \multicolumn{2}{|c|}{$7^{\circ} \mathrm{dia}$} & \multicolumn{2}{|c|}{$14^{\circ} \mathrm{dia}$} & \multicolumn{2}{|c|}{$21^{\circ}$ dia } & \multicolumn{2}{|c|}{$28^{\circ}$ dia } & \multicolumn{2}{|c|}{$31^{\circ}$ dia } & \\
\hline & $\% M^{1}$ & Classe $^{2}$ & $\% M^{1}$ & Classe $^{2}$ & $\% \mathrm{M}^{1}$ & Classe $^{2}$ & $\% \mathbf{M}^{1}$ & Classe $^{2}$ & $\% \mathrm{M}^{1}$ & Classe $^{2}$ & \\
\hline Abamectina & 16,00 & 1 & 17,20 & 1 & 16,2 & 1 & 12,40 & 1 & 8,80 & 1 & Vida curta \\
\hline Testemunha & 5,00 & - & 8,00 & - & 6,0 & - & 7,40 & - & 4,40 & - & - \\
\hline
\end{tabular}

1 Porcentagem de mortalidade de fêmeas de Neoseiulus californicus.

2 Classe de toxicidade dos compostos em condições de semi-campo (HASSAN, 1997): A = vida curta ( $<5$ dias), $\mathrm{B}=$ pouco persistente ( 5 a 15 dias), $\mathrm{C}=$ moderadamente persistente (16 a 30 dias) e $\mathrm{D}=$ persistente ( $>30$ dias).

Fonte: Elaboração própria.

\section{Conclusões}

O composto abamectina foi prejudicial ao predador $N$. californicus, sendo considerado nocivo para aplicação direta.

Os compostos milbemectina, propargito e iprodiona foram levemente nocivos ao predador $N$. californicus, enquanto os compostos enxofre, fempropatrina, cihexatina foram inócuos.

Em condições de semi-campo, o efeito residual do composto abamectina não foi prejudicial para N. californicus.

A associação de produtos de baixa toxicidade aos predadores $N$. californicus em manejo integrado pode representar uma boa estratégia no controle do ácaro-rajado em cultivos de morangueiro, além de representar um importante mecanismo para proteção do meio ambiente e redução do impacto ambiental, principalmente quando a associação ocorrer no início da implementação do cultivo.

\section{Impact of strawberries cultivation pesticides on the population of Neoseiulus californicus predator (McGregor) (Acari: Phytoseiidae)}

\section{Abstract}

The two-spotted spider mite, Tetranychus urticae Koch, is considered one of the main pest of strawberry crop. Chemical control has been widely used to control this mite. Neoseiulus californicus is an efficient predator of $T$. urticae. The aim of this study was to evaluate the selectivity of some chemicals sprayed on strawberry crops to the predatory mite $N$. californicus, at laboratory conditions. The bioassay was conducted at the Laboratory of Entomology of Federal Institute of south of Minas State of Minas Gerais, Brazil. The evaluated products were abamectin, sulfur, fenpropathrin, propargite, milbemectin, cyhexatin and iprodione, besides $\mathrm{H}_{20}$ as witness. The products were sprayed directly on 
predatory mites, using calibrated sprayers. The parameter evaluated was the mortality of predatory mites. The results showed that according to IOBC classification, abamectin is harmful; milbemectin, iprodione and propargite are slightly harmful; and sulfur, fenpropathrin and cihexatin are no harmful to $N$. californicus. The chemicals considered slightly and no harmful to $N$. californicus are promising to Integrated Pest Management of $T$. urticae on strawberry crops.

Keywords: Selectivity. Predatory mite. Chemical products. Integrated Pest Management.

\section{Agradecimentos}

Agradecimento especial à Fapemig pelos recursos financiadores e pela concessão da bolsa de iniciação científica do primeiro autor, sem a qual impossibilitaria a realização do projeto.

À Empresa Promip (Paulínia-SP), pela cessão dos indivíduos de $N$. californicus para a criação de manutenção.

Ao amigo Carlos Augusto de Lima, pelo apoio no desenvolvimento deste trabalho.

Os autores agradecem também o apoio das instituições parceiras (Emater, Embrapa, Instituto Biológico, Esalq, Epamig e IMA) e aos produtores de morango do sul de Minas Gerais, que juntos buscam o desenvolvimento sustentável da cultura.

\section{Referências bibliográficas}

ABBOTT, W. S. A method of computing the effectiveness of an insecticide. Journal of Economic Entomology. Lanham, v.18, n.2, p.265-267, 1925.

ANTUNES, L. E. C. et al. Implementação da produção integrada de morangos no Rio Grande do Sul e Sul de Minas Gerais. Projeto de pesquisa aprovado pelo CNPq 2005/2007. Processo CNPq 48.0012/04-0. Embrapa Clima Temperado. Disponível em <http://www.cpact.embrapa.br/ programas_projetos/projetos/Relacao\%20de\%20projetos/projetos_apropriados.php $>$. Acesso em: 19 mar 2013.

BAKKER, F. et al. Side-effect tests for Phytoseiids and their rearing methods. IOBC/WPRS, Bulletin SROP, Montfavet, v.15, n.3, p.61-81, 1992.

CARVALHO, G.A.; CARVALHO, C.F.; FERREIRA, M.N. Toxicidade de acaricidas a ovos e adultos de Ceraeochrysa cubana (Hagen, 1861) (Neuroptera: Chrysopidae). Ciência \& Agrotecnologia. Lavras, v.35, n.1, p. 165-171, jan./fev. 2011. Disponível em: <http://www.scielo.br/scielo. php?script $=$ sci_arttext\&pid=S1413-70542011000100021 >. Acesso em: 19 mar. 2013.

CARVALHO, S. P.(Coord.). Boletim do Morango: cultivo convencional, segurança alimentar, cultivo orgânico. Belo Horizonte: FAEMG, 2006. 160 p.

CLELAND, T. A. Inhibitory glutamate-receptor channels. Molecular Neurobiology, Firenze, v.13, n.2, p.97-136, 1996. Disponível em: <http://link.springer.com/article/10.1007/BF02740637>. Acesso em 20 mar. 2013.

DEGRANDE, P. E. et al. Metodologia para avaliar o impacto de pesticidas sobre inimigos naturais. In: PARRA, J. R. P.; BOTELHO, P. S. M.; CORRÊA-FERREIRA, B. S.; BENTO, J. M. S. (Ed.)

Controle biológico no Brasil: parasitoides e predadores. São Paulo: Manole, 2002. p. 71-94. 
EMATER-MG. EMPRESA DE ASSISTÊNCIA TÉCNICA E EXTENSÃO RURAL DO ESTADO DE MINAS GERAIS. Disponível em: <http://www.emater.mg.gov.br/portal.cgi?flagweb=site_tpl_paginas_ internas\&id=7916> . Acesso em 22 set. 2011.

ENGLISH-LOEB, G.; HESLER, S. Economic impact of the two-spotted spider mites (Tetranychus urticae) on strawberries grown as a perennial. New York Berry News, New York, v.4, n.1, p.15, 2005. Disponível em: <http://www.fruit.cornell.edu/nybn/newslettpdfs/2005/nybn41a.pdf>. Acesso em 20 mar. 2013.

FADINI, M. A. M.; ALVARENGA, D. A. Pragas do morangueiro. Informe Agropecuário, Belo Horizonte, v.20, n.198, p.69-74, maio/jun 1999.

FERREIRA, D. F. SISVAR: UM PROGRAMA PARA ANÁLISES E ENSINOS DE ESTATÍSTICAS. REVISTA SYMPOSIUM, LAVRAS, V.6, N.2, P.36-41, 2008.

FLECHTMANN, C. H. W. Ácaros de importância agrícola. São Paulo: Nobel, 1985.

FREITAS, J. A. et al.. Produtores de morango no município de Bom Repouso relatam Tetranychus urticae Koch como principal problema da cultura. In: SIMPÓSIO BRASILEIRO DE ACAROLOGIA, 3, 2011. Campinas. Resumos... São Paulo: 3, 2011. p.1a.

HASSAN, S. A. Guideline for the evaluation of side-effects of plant protection product on Trichogramma cacoeciae. IOBC/WPRS Bulletin SROP, Montfavet, v.15, n.3, p.18-39, abr. 1992.

HASSAN, S. A. Métodos padronizados para testes de seletividade com ênfase em Trichogramma. In: PARRA, J.R.P.; ZUCCHI, R.A. (Ed.). Trichogramma e o controle biológico aplicado. Piracicaba: FEALQ, 1997. Cap. 8, p.207-233.

HASSAN, S. A. Production of the Angoumois grain Sitotroga cerealella (Oliv.) as an alternative host for egg parasites. In: GERDING, P. M. (Ed.). Producción y utilización de Trichogramma para el control biológico de plagas. Chillán: Taller International, 1994. p. 20-26.

HODDLE, M. S.; ROBINSON, L.; VIRZI, J. Biological control of Olygonychus perseae (Acari: Tetranychidae) on avocado: III. Evaluating the efficacy of varying release rates and releases frequency of Neoseiulus californicus (Acari: Phytoseiidae). International Journal Acarology, [s.I.], v.26, p.203-214, 2000.

MCMURTRY, J. A.; CROFT, B. A. Life styles of phytoseiid mites and their roles as biological control agents. Annual Review of Entomology, Palo Alto, v.42, p.291-321, 1997.

MORAES, G. J. Controle biológico de ácaros fitófagos com predadores. In: PARRA, J. R. P.; BOTELHO, P. S. M.; CORRÊA-FERREIRA, B. S.; BENTO, J. M. S. (Ed.) Controle biológico no Brasil: parasitóides e predadores. São Paulo: Manole, 2002. p.225-237.

POLETTI, M.; COLLETTI, L. P.; OMOTO, C. Compatibilidade de Agrotóxicos com Ácaros Predadores neoseiulus californicus (McGregor) e Phytoseiulus macropilis (Banks) (Acari: Phytoseiidae).

BioAssay, Piracicaba, v. 3, n.3, p. 01-14, 2008. Disponível em:<http://www.bioassay.org.br/ bioassay/article/viewFile/58/90>Acesso em 20 mar. 2013. 
RESENDE, L.M.A.; MASCARENHAS, M.H.T.; PAIVA, B.M. Panorama da produção e comercialização de morango. Informe Agropecuário, Belo Horizonte, v.20, n.198, p.5-19, 1999.

STERK, G.; VANWETSWINKEL, G.; A field method for testing for the side-effects of pesticides on the predatory mite Amblyseius finlandicus (oud.) (Phytoseiidae: Acari). IOBC/WPRS. Bulletin, Montfavet, v. 4, p. 137, 1988.

STRONG, W. B.; CROFT, B. A. Inoculative relaese of phytoseiid mites (Acarina: Phytoseidae) into the rapidly expanding canopy of hop for control of Tetranychus urticae (Acarina: Tetranychidae). Environmental Entomology, Washington, v.24, p.446-453, 1995.

VEIRE, M. van de; SMAGGHE, G.; DEGHEELE, D. A laboratory test method to evaluate the effect of 31 pesticides on the predatory bug, Orius laevigatus (Heteroptera: Anthocoridae). Entomophaga, Paris, v.41, n.2, p.235-243, 1996.

VEIRE, van de; STERK, G.; STAAIJ, M. van der, M.; RAMAKERS, P.M.J.; TIRRY, L. Sequential testing scheme for the assessment of the side-effects of plant protection products on the predatory bug Orius laevigatus. BioControl, Dordrecht, v.47, n.1, p.101-113, feb. 2002.

VERONEZ, B. et al. Seletividade de produtos fitossanitários utilizados na cultura do morangueiro a Phytoseiulus macropilis (Banks) (Acaro: Phytoseiidae) em condições de laboratório. Revista Agrogeoambiental, Inconfidentes, v.1, n. 02, p. 70-81, 2009.

WETZEL, C.; DICKLER, E. Side effects of sulphur and a natural pyrethroid on Trichogramma dendrolimi Matsumura (Hym., Trichogrammatidae) in apple orchards. In: INTERNATIONAL ORGANIZATION FOR BIOLOGICAL CONTROL OF NOXIOUS ANIMALS AND PLANTS. Working group "pesticides and beneficial organisms. Bulletin SROP, Montfavet, v.17, n.10, 1994. p.123131.

\section{Histórico editorial}

Recebido: 13/02/2013

Avaliação e copidesque: 21/02/2013 a 28/03/2013 